\title{
Study on the Relationship between Nursing Staffing and Nosocomial Infection in Very Low Birth Weight Infants
}

\author{
Li He${ }^{1}$, Chaomei Huang1 ${ }^{*}$, Xiaoqin Jia1, Jianning Xie ${ }^{1}$, Hui Yang² \\ ${ }^{1}$ Department of Neonatology, Foshan Women and Children's Hospital, Foshan, China \\ ${ }^{2}$ Shunde iBorn Women's \& Children's Hospital, Foshan, China \\ Email: *342173150@qq.com
}

How to cite this paper: He, L., Huang, C.M., Jia, X.Q., Xie, J.N. and Yang, H. (2020) Study on the Relationship between Nursing Staffing and Nosocomial Infection in Very Low Birth Weight Infants. Journal of Biosciences and Medicines, 8, 179-186. https://doi.org/10.4236/jbm.2020.811016

Received: October 15, 2020

Accepted: November 21, 2020

Published: November 24, 2020

Copyright $\odot 2020$ by author(s) and Scientific Research Publishing Inc. This work is licensed under the Creative Commons Attribution International License (CC BY 4.0).

http://creativecommons.org/licenses/by/4.0/

(c) (i) Open Access

\begin{abstract}
Background: At present, there is no domestic research on the relationship between nurse staffing and hospital infection in very low birth weight infants. In this paper, we will explore the relationship between nurses of very low birth weight (VLBW) infants in neonatal intensive care unit (NICU) and nosocomial infections. Methods: The clinical data of 280 very low birth weight infants born in our hospital from January 2010 to January 2020 were collected, and the chi-square test and multiple logistic regression analysis were used to study the nursing staff of each very low birth weight infant who was admitted to the NICU The relationship between the number of infections and hospital infections. Results: On average, each nurse needs to care for 4.3 very low birth weight infants (lowest to highest: 2.50 - 8.42). In the univariate analysis, the higher the incidence of urinary tract infection $(\mathrm{P}<0.05)$, the multivariate logistic regression analysis of neonatal nosocomial infection showed that nurse staffing was significantly related to the incidence of urinary tract infection $(\mathrm{OR}=1.78 ; 95 \%$ confidence interval, $1.17-2.35, \mathrm{P}<0.05)$. However, there was no significant correlation between nurse staffing and bloodstream infection $(\mathrm{OR}=0.91 ; 95 \%$ confidence interval, $0.74-1.06, \mathrm{P}>0.05)$ or Ventilator associated pneumonia (VAP) infection $(\mathrm{OR}=1.17$; $95 \%$ confidence interval, $0.94-1.47, \mathrm{P}>0.05)$. Conclusion: Our research shows that in the neonatal intensive care unit, the reasonable deployment of nursing staff is an important factor in preventing urinary tract infections in very low birth weight infants. It is important for improving the survival rate of very low birth weight infants and reducing the occurrence of sequelae.
\end{abstract}

\section{Keywords}

Neonatal Intensive Care Unit, Nursing Staff, Urinary Tract Infection, Very Low Birth Weight Infants 


\section{Introduction}

Very low birth weight infants (VLBW) refer to premature infants whose birth weight is less than $1500 \mathrm{~g}$ [1]. Very low birth weight infants usually have a gestational age of less than 30 weeks, and their organs are extremely immature and have a high risk of nosocomial infection. The newborn with the highest mortality and disability rate, and the incidence of very low birth weight infants is $1.25 \%$ [2] [3] [4] [5]. With the continuous advancement of neonatal medical technology and perinatal medicine, the rescue success rate of very low birth weight infants has greatly increased, but the quality of life is not optimistic. Research data at home and abroad shows that survival of very low birth weight infants have different degrees of cerebral palsy. Cognitive impairment, audiovisual impairment, etc., bring heavy economic and spiritual burdens to society and families, and the quality of care plays a very important role in the mortality and disability rate of very low birth weight infants in the neonatal intensive care unit (NICU) Effect [6] [7] [8], studies have reported that in 67 intensive care units in the United States, the shortage of nursing staff is closely related to the incidence of nosocomial infections in ultra-low birth weight infants, and the infection rate is significantly increased [9]. This study analyzes the clinical data of 280 very low birth weight infants born in our hospital to study neonatal intensive care. The relationship between nurses for very low birth weight (VLBW) infants in the ward (NICU) and nosocomial infections to improve the success rate of treatment for very low birth weight infants.

\section{Methods}

\subsection{General Information}

Collect the clinical data of 280 extremely low birth weight infants born in Foshan women and children's hospital from January 2010 to January 2020. These clinical data include the sex, birth weight, gestational age, diagnosis and clinical related operations of the children. The configuration of nurse staff is defined as the number of newborns nursed by each nurse. The nurses in this study only include registered nurses. The nursing time required by the child is calculated by multiplying the number of hospitalization days of all hospitalized children in a year by 24 . The full-time nursing staff in our hospital need to work an average of 40 hours a week, but the actual time for newborn care accounts for about $85 \%$ of the total weekly working time, excluding full-time work such as vacation, sick leave, education and management tasks time. Therefore, by multiplying the number of nurses by 40 hours per week, and then multiplying by the result 0.85 , the time spent in neonatal care can be obtained. This study was approved by the Medical Ethics Committee of Foshan women and children's hospital.

\subsection{Hospital Infection}

We choose to statistically analyze three types of nosocomial infections, namely blood infections, urinary tract infections and rotavirus infections. Because these 
three types of nosocomial infections are the most common infections in neonatology and are very sensitive to assessing the quality of NICU care, the nosocomial infections in this study refer to blood infections, urinary tract infections and rotas as the main diagnoses secondary to hospitalization. One of the viral infections, and therefore, very low birth weight infants who have been hospitalized for at least 3 days.

\subsection{Clinical Characteristics of Very Low Birth Weight Infants}

According to domestic and foreign literature reports, the following clinical characteristics are selected as the most variables: birth weight, gestational age at birth, gender, insurance type, year of admission, multiple births, birth defects, mechanical ventilation, surfactant injection, central venous catheterization, stomach Number of parenteral nutrition, operations and second diagnosis. Birth defects include major birth defects stipulated in our country, and surgery refers to an operation that takes 1 hour or more under general anesthesia. The number of second diagnoses refers to the number of diagnoses for each newborn except the first (main) diagnosis.

\subsection{Data Analysis}

Review the validity of the research data. Use SPSS 26.0 software to implement double entry and establish a database, statistical analysis and processing of data, in order to analyze the relationship between nurse staffing and nosocomial infection, multiple linear regression analysis was used, and chi-square test was used for measurement data, $\mathrm{P}<0.05$ The difference is statistically significant.

\section{Result}

This study found that about two-thirds of preterm infants had a birth weight of 1000 to $1499 \mathrm{~g}$ and a gestational age of 28 to 36 weeks. About $20 \%$ of very low birth weight infants have congenital defects. All very low birth weight infants were ventilated with a ventilator and injected with alveolar surfactants, the proportions of which were about $80 \%$ and $65 \%$, respectively, as shown in Table 1 .

The average number of very low birth weight infants nursed by each nurse was 4.30 (lowest to highest: $2.50-8.42$ ). The incidence of urinary tract infection and rotavirus infection increased significantly as the number of children nursed by each nurse increased, and the difference was statistically significant $(\mathrm{P}<$ 0.05). The incidence of blood infection increased with the increase in the number of patients nursed by each nurse. The increase in the number of children does not increase significantly, see Table 2 .

The results of multiple logistic regression analysis for neonatal hospital infections showed that nurse staffing was significantly related to the incidence of urinary tract infections $(\mathrm{OR}=1.78 ; 95 \%$ confidence interval, 1.17 - 2.35). However, there is no significant correlation between nurse staffing and bloodstream infection $(\mathrm{OR}=0.91 ; 95 \%$ confidence interval, $0.74-1.06)$ or rotavirus infection (OR 
$=1.17 ; 95 \%$ confidence interval, $0.94-1.47)$. See Table 3.

\section{Discussion}

Nosocomial infection is the most important and fatal complication of very low birth weight infants. Children with NICU are susceptible to nosocomial infections [10] [11]. In recent years, the treatment and prognosis of infants with birth

Table 1. Basic characteristics of children.

\begin{tabular}{|c|c|c|c|c|}
\hline & Variable & Category & $\begin{array}{c}\mathrm{N}(\%) \text { or } \\
\text { mean } \pm \mathrm{SD}\end{array}$ & Min-max \\
\hline \multirow[t]{16}{*}{ Children $(\mathrm{n}=280)$} & birth weight & $<1000 \mathrm{~g}$ & $110(39.3)$ & \\
\hline & & $1000-1499 \mathrm{~g}$ & $170(60.7)$ & \\
\hline & Pregnancy age & $<28$ Week & $98(35.0)$ & \\
\hline & & $28-36$ Week & $182(65.0)$ & \\
\hline & Gender & male & $142(50.7)$ & \\
\hline & & female & $138(49.3)$ & \\
\hline & branch of insurance & Health insurance & $273(97.5)$ & \\
\hline & & medical assistance & $7(2.5)$ & \\
\hline & polyembryony & Yes & $30(10.7)$ & \\
\hline & Birth defects & Yes & $48(17.1)$ & \\
\hline & Mechanical ventilation & Yes & $228(79.6)$ & \\
\hline & $\begin{array}{l}\text { Application of alveolar } \\
\text { surfactant drugs }\end{array}$ & Yes & $183(65.4)$ & \\
\hline & Central venous catheterization & Yes & $173(61.8)$ & \\
\hline & Total parenteral nutrition & Yes & $133(47.5)$ & \\
\hline & operation & Yes & $27(9.6)$ & \\
\hline & Number of secondary diagnoses & & $14.1 \pm 8.4$ & $2.0-18.0$ \\
\hline
\end{tabular}

Table 2. The relationship between nursing staff and the incidence of nosocomial infection.

\begin{tabular}{|c|c|c|c|c|c|c|c|c|c|c|}
\hline \multirow{2}{*}{ Variable } & \multirow{2}{*}{ Category } & \multicolumn{3}{|c|}{ Blood infection rate } & \multicolumn{3}{|c|}{$\begin{array}{l}\text { Urinary tract } \\
\text { infection rate }\end{array}$} & \multicolumn{3}{|c|}{ VAP infection rate } \\
\hline & & $\%$ & $\mathrm{SD}$ & $\mathrm{P}$ & $\%$ & SD & $\mathrm{P}$ & $\%$ & SD & $\mathrm{P}$ \\
\hline \multirow{3}{*}{$\begin{array}{c}\text { Number of } \\
\text { newborns/ } \\
\text { nurses }\end{array}$} & $<4$ & 13.6 & 14.1 & 0.395 & 1.8 & 2.6 & 0.02 & 5.7 & 5.0 & 0.025 \\
\hline & $4-5.9$ & 13.9 & 16.8 & & 3.9 & 3.7 & & 10.7 & 14.9 & \\
\hline & $\geq 6$ & 17.5 & 20.4 & & 15.4 & 18.2 & & 20.4 & 25.9 & \\
\hline
\end{tabular}

Table 3. Multiple logistic regression analysis between nursing staff and hospital infection.

\begin{tabular}{cccc}
\hline Variable & $\begin{array}{c}\text { Blood infection rate } \\
\text { Adjusted OR }(95 \% \mathrm{CI})\end{array}$ & $\begin{array}{c}\text { Urinary tract infection rate } \\
\text { Adjusted OR }(95 \% \mathrm{CI})\end{array}$ & $\begin{array}{c}\text { VAP infection rate } \\
\text { Adjusted OR (95\% CI) }\end{array}$ \\
\hline $\begin{array}{c}\text { Number of } \\
\text { patients/each } \\
\text { nurse }\end{array}$ & $0.91(0.74-1.06)$ & $1.78(1.17-2.35)$ & $1.17(0.94-1.47)$ \\
\hline
\end{tabular}


weight have attracted much attention. The survival rate of very low birth weight infants admitted to NICU has been significantly improved. The prognosis of survival infants has also been continuously improved through unremitting efforts [12] [13] [14] [15]. Therefore, hospitals should attach great importance to it. NICU management, dedicated care, washing hands before and after contact, reducing the flow of people, and purifying the air are important measures to prevent the occurrence of nosocomial infections. First of all, it is necessary to rationally allocate physical and mental health, professional nursing staff with good psychological quality, and pay attention to the combination of senior and experienced young nurses to adapt to the intense and heavy work. At the same time, the nursing decisions should be clear and provide high-quality services to the children. Secondly, nurses must have the concept of aseptic technology. Before performing invasive operations on children, they must perform strict aseptic disinfection of the palms, and backs of the hands, with gentle movements to avoid damage to the local mucosa, and the used medical equipment should be sent to the supply room for disinfection in time. Do a good job of routine care for various indwelling pipelines, pull out as soon as possible, and replace the drainage bag once every 24 hours for pipelines that cannot be pulled out; and regularly observe the nature, smell, volume, and color of the drainage night. Nosocomial infection is bound to occur. Increasing the number of days of hospitalization increases the cost of hospitalization. At present, there is no standard for the provision of NICU nursing staff in China [16] [17]. Studies abroad have found that for newborns in need of intensive care, the ratio of nurses to newborns should be 1:1 to 1:2, for newborns who need intermediate care, the ratio of nurses to babies should be 1:2 to 1:3, for newborns who need continuous care, the ratio should be 1:3 to 1:4, for healthy newborns. The ratio should be $1: 5$ to $1: 6$ [18]-[23]. The responsible nurse is the main implementer of all treatment and nursing care during the hospitalization process. It plays an important role in reducing hospital complications. The 24-hour responsibility system allows the responsible nurse to fully understand the child's condition and recognize subtle changes. According to the oxygen regulations for preterm infants, control the oxygen saturation at $85 \%$ - $95 \%$ to reduce the occurrence of retinopathy of prematurity (ROP); during mechanical ventilation, strengthen respiratory management, closely observe the condition, and apply low tidal volume and allowable hypercapnia. Protective ventilation strategy for the disease, maintain a stable environment in the body and reduce the occurrence of bronchopulmonary dysplasia (BPD); various operations are concentrated, and various treatment and nursing measures are in place, so that intraventricular hemorrhage (IVH) and necrotizing enterocolitis (NEC). And other incidence rates are reduced to the lowest point [24] [25]; therefore, hospitalization complications can affect the prognosis of very low birth weight infants, reduce the incidence of complications during hospitalization, and significantly improve the prognosis of very low birth weight infants.

The purpose of this study was to determine the relationship between nurses in 
the neonatal intensive care unit (NICU) for very low birth weight (VLBW) infants and nosocomial infections. The results of the study show that about twothirds of premature babies have a birth weight of 1000 to $1499 \mathrm{~g}$ and a gestational age of 28 to 36 weeks. Approximately $17.1 \%$ of very low birth weight infants have congenital defects. All very low birth weight infants were ventilated with a ventilator and injected with alveolar surfactants. The proportions were $79.6 \%$ and $65.4 \%$, respectively, for neonatal hospital infections. The results of multiple logistic regression analysis showed that nurse staffing was significantly related to the incidence of urinary tract infection $(\mathrm{OR}=1.78 ; 95 \%$ confidence interval, 1.17 - 2.35). However, there was no significant correlation between nurse staffing and bloodstream infection $(\mathrm{OR}=0.91 ; 95 \%$ confidence interval, $0.74-1.06)$ or rotavirus infection $(\mathrm{OR}=1.17 ; 95 \%$ confidence interval, $0.94-1.47)$. In our research, we found that blood infections in very low birth weight infants have nothing to do with nurse staffing. This is different from the results of some foreign studies. In a study of 108 neonatal intensive care units in Germany, it was found that reduced nurse staffing will increase the risk of central venous catheter-related bloodstream infections in very low birth weight infants. Rotavirus is a common nosocomial viral infection in newborns, which can cause diarrhea and even death in newborns. The study did not find that rotavirus infection in very low birth weight infants was related to nurse staffing. Therefore, in the next step, we will further study the related factors of rotavirus. At present, our research only confirms that clinical nursing staff is related to the incidence of urinary tract infections in very low birth weight infants, but whether it is related to other nosocomial infections. Clearly, such as ventilator-associated pneumonia, postoperative wound infection, etc. Therefore, we need further research to determine whether other nosocomial infections are related to nursing staff. In addition, we recommend the prevention and control of nosocomial infections in newborns. In addition to providing appropriate nursing staff, we should also strengthen the assessment of the quality of NICU care and continuous hospital-sensing training.

At present, there is no domestic research on the relationship between nurse staffing and nosocomial infection in very low birth weight infants. The results of this study provide evidence for the clinical nursing staffing on the incidence of urinary tract infection in very low birth weight infants. It is recommended that the neonatal intensive care unit should actively modify the nurse staffing policy, which will help reduce the incidence of nosocomial infections, increase the survival rate of very low birth weight infants, reduce hospitalization complications, and promote the healthy growth of very low birth weight infants.

\section{Conflicts of Interest}

The authors declare no conflicts of interest regarding the publication of this paper.

\section{References}

[1] Profit, J., Petersen, L.A., McCormick, M.C., et al. (2010) Patient-to-Nurse Ratios and Outcomes of Moderately Preterm Infants. Pediatrics, 125, 320-326. 
https://doi.org/10.1542/peds.2008-3140

[2] Li, J.H. and Mu, D.Z. (2020) Discussion on Hot Issues in Clinical Management of Preterm Infants. Chinese Journal of Maternal and Child Clinical Medicine (Electronic Edition), 16, 1-7.

[3] Kaplan, H.C., Lorch, S.A., Pinto-Martin, J., Putt, M. and Silber, J.H. (2011) Assessment of Surfactant Use in Preterm Infants as a Marker of Neonatal Intensive Care Unit Quality. BMC Health Services Research, 11, Article No.: 22. https://doi.org/10.1186/1472-6963-11-22

[4] Cheng, J., Yu, Z.B., Qiu, Y.F., et al. (2020) The Effect of Admission Body Temperature on the Clinical Outcome of Very/Ultra-Low Birth Weight Infants. Journal of Nanjing Medical University, No. 4, 600-603.

[5] Brennan, P.F. and Bakken, S. (2015) Nursing Needs Big Data and Big Data Needs Nursing. Journal of Nursing Scholarship, 47, 477-484. https://doi.org/10.1111/jnu.12159

[6] McConnell, E.A., Birkett, M. and Shattell, M. (2015) The Future of Big Data: Innovative Methodological Approaches. Issues in Mental Health Nursing, 36, 478-480. https://doi.org/10.3109/01612840.2015.1017626

[7] Spetz, J., Donaldson, N., Aydin, C. and Brown, D.S. (2008) How Many Nurses per Patient? Measurements of Nurse Staffing in Health Services Research. Health Services Research, 43, 1674-1692. https://doi.org/10.1111/j.1475-6773.2008.00850.x

[8] Cimiotti, J.P., Haas, J., Saiman, L. and Larson, E.L. (2006) Impact of Staffing on Bloodstream Infections in the Neonatal Intensive Care Unit. Archives of Pediatrics and Adolescent Medicine, 160, 832-836. https://doi.org/10.1001/archpedi.160.8.832

[9] Rogowski, J.A., Staiger, D., Patrick, T., Horbar, J., Kenny, M. and Lake, E.T. (2013) Nurse Staffing and NICU Infection Rates. JAMA Pediatrics, 167, 444-450. https://doi.org/10.1001/jamapediatrics.2013.18

[10] Salem, M.R. and Youssef, M.R.L. (2017) Health Care Providers' Perspectives for Providing Quality Infection Control Measures at the Neonatal Intensive Care Unit, Cairo University Hospital. American Journal of Infection Control, 45, 99-102. https://doi.org/10.1016/j.ajic.2017.03.013

[11] Yu, S. and Kim, T.G. (2015) Evaluation of Nurse Staffing Levels and Outcomes under the Government-Recommended Staffing Levels in Korea. Journal of Nursing Management, 23, 479-486. https://doi.org/10.1111/jonm.12155

[12] Cho, S.-H. (2003) Using Multilevel Analysis in Patient and Organizational Outcomes Research. Nursing Research, 52, 61-65. https://doi.org/10.1097/00006199-200301000-00010

[13] Feng, Z.S., Wu, F., Jia, C.H., et al. (2020) Clinical Treatment of Ultra-Immature Infants. Electronic Journal of Developmental Medicine, No. 1, 60-66.

[14] Crealey, M.R., Bowden, L., Ludusan, E., Pathan, M., Kenny, B., Hannigan, A., et al. (2019) Utilization of Conventional Radiography in a Regional Neonatal Intensive Care Unit in Ireland. The Journal of Maternal-Fetal \& Neonatal Medicine, 32, $2667-$ 2673. https://doi.org/10.1080/14767058.2018.1445713

[15] Teišerskas, J., Bartašienè, R. and Tamelienè, R. (2019) Associations between Red Blood Cell Transfusions and Necrotizing Enterocolitis in Very Low Birth Weight Infants: Ten-Year Data of a Tertiary Neonatal Unit. Medicina, 55, 16. https://doi.org/10.3390/medicina55010016

[16] Hu, X.Y., Chang, Y.M. and Li, Z.L. (2020) Clinical Features and Risk Factors of Feeding Intolerance in Preterm Infants. Chinese Journal of Perinatal Medicine, 23, 
182-187.

[17] Kim, C.-G. and Bae, K.-S. (2018) Relationship between Nurse Staffing Level and Adult Nursing-Sensitive Outcomes in Tertiary Hospitals of Korea: Retrospective Observational Study. International Journal of Nursing Studies, 80, 155-164. https://doi.org/10.1016/j.ijnurstu.2018.01.001

[18] Yee, A.L., Miller, E., Dishaw, L.J., Gordon, J.M., et al. (2019) Longitudinal Microbiome Composition and Stability Correlate with Increased Weight and Length of Very-Low-Birth-Weight Infants. mSystems, 4, 11-15. https://doi.org/10.1128/mSystems.00229-18

[19] Foglia, E.E. and Lorch, S.A. (2012) Clinical Predictors of Urinary Tract Infection in the Neonatal Intensive Care Unit. Journal of Neonatal-Perinatal Medicine, 5, 327-333. https://doi.org/10.3233/NPM-1262812

[20] Levy, I., Comarsca, J., Davidovits, M., Klinger, G., Sirota, L. and Linder, N. (2009) Urinary Tract Infection in Preterm Infants: The Protective Role of Breastfeeding. Pediatric Nephrology, 24, 527-531. https://doi.org/10.1007/s00467-008-1007-7

[21] Ruangkit, C., Satpute, A., Vogt, B.A., Hoyen, C. and Viswanathan, S. (2016) Incidence and Risk Factors of Urinary Tract Infection in Very Low-Birth-Weight Infants. Journal of Neonatal-Perinatal Medicine, 9, 83-90. https://doi.org/10.3233/NPM-16915055

[22] Leistner, R., Thurnagel, S., Schwab, F., Piening, B., Gastmeier, P. and Geffers, C. (2013) The Impact of Staffing on Central Venous Catheter-Associated Bloodstream Infections in Preterm Neonates Results of Nation-Wide Cohort Study in Germany. Antimicrobial Resistance and Infection Control, 2, Article No.: 11. https://doi.org/10.1186/2047-2994-2-11

[23] Sovie, M.D. and Jawad, A.F. (2001) Hospital Restructuring and Its Impact on Outcomes: Nursing Staff Regulations Are Premature. The Journal of Nursing Administration, 31, 588-600. https://doi.org/10.1097/00005110-200112000-00010

[24] Lu, J., Tan, S.R., Wei, H.F. and Li, Y. (2018) To Explore the Related Factors and Countermeasures of Nosocomial Infection in Patients in Intensive Care Unit. Heilongjiang Medicine, 42, 262-263.

[25] Beltempo, M., Blais, R., Lacroix, G., Cabot, M. and Piedboeuf, B. (2017) Association of Nursing Overtime, Nurse Staffing, and Unit Occupancy with Health Care-Associated Infections in the NICU. American Journal of Perinatology, 34, 996-1002. https://doi.org/10.1055/s-0037-1601459 